Article

\title{
Hybrid Bayesian Network Models of Spinal Injury and Slip/Fall Events
}

\section{Richard Hughes}

Departments of Orthopaedic Surgery, Biomedical Engineering, and Industrial \& Operations Engineering, University of Michigan, Ann Arbor, MI 48109, USA; rehughes@umich.edu; Tel.: +1-734-474-2459

Received: 10 April 2020; Accepted: 9 July 2020; Published: 14 July 2020

Featured Application: Forensic analysis of occupational injuries for use in civil litigation.

Abstract: Background: Biomechanists are often asked to provide expert opinions in legal proceedings, especially personal injury cases. This often involves using deterministic analysis methods, although the expert is expected to opine using a civil standard of "more likely than not" that is inherently probabilistic. Methods: A method is proposed for converting a class of deterministic biomechanical models into hybrid Bayesian networks that produce a probability well suited for addressing the civil standard of proof. The method was developed for spinal injury during lifting. Its generalizability was assessed by applying it to slip and fall events based on the coefficients of friction at the shoe-floor interface. Results: The proposed method is shown to be generalizable beyond lifting by applying it to a slip and fall event. Both the lifting and slip and fall models showed that incorporating evidence of injury could change the probabilities of critical quantities exceeding a threshold from "less likely than

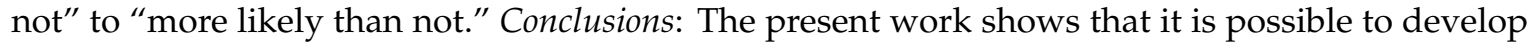
Bayesian networks for legal use based on laws of engineering mechanics and probabilistic descriptions of measurement error and human variability.

Keywords: biomechanics; Bayesian network; artificial intelligence; spine; slip and fall; litigation; tort

\section{Introduction}

Biomechanics has many applications, including litigation. Expert witnesses play an important role in personal injury legal cases. In industries lacking workers' compensation insurance (interstate railroads and maritime in the United States), experts in biomechanics are often retained to analyze workplace factors and opine on whether they were responsible for the injury central to a civil case against the employer. Litigation can also extend to manufacturers of equipment in industries with no-fault workers' compensation. Low back injuries are well known to be sources of employee litigation. Outside the workplace, injuries resulting from slips and falls lead to civil lawsuits against landlords, businesses, and others responsible for maintaining walking surface conditions.

Biomechanists serving as expert witnesses rely on adaptations of the standard methods of forensic engineering and applied research. Case materials are reviewed and site visits are made to make workplace and environmental measurements. Literature reviews are performed, and engineering analyses conducted. Analysis methods include mathematical and computational models. There are typically two issues lawyer may ask a biomechanics expert to opine about: (1) causation, and (2) negligence. For cases related to negligence, the retaining lawyer seeks an opinion about whether the employer failed to meet a generally accepted standard.

The expert is expected to state an opinion that is held to a "reasonable scientific certainty" or a "reasonable degree of engineering certainty" [1]. Since these phrases are not regularly used in science and engineering, they can be challenging to operationalize for the expert. However, the U.S. Court of 
Appeals stated that "reasonable degree of scientific certainty" means "more likely than not" in Burke v. Town of Walpole [2]. Unfortunately, traditional computational analysis methods used by biomechanists are not well suited for addressing a probabilistic standard because they are deterministic.

The purpose of this project was to develop a methodology for creating hybrid Bayesian network implementations of biomechanical models that can be used to develop an opinion on negligence using the "more likely than not" interpretation of "reasonable scientific certainty" in civil litigation. The manuscript is organized into three sections: (1) description of the general method, (2) application of the general method to two examples (spinal injury during lifting and slip-induced fall injury during gait), and (3) a discussion. The relevance to the theme of this special issue is that Bayesian networks, which were developed in the artificial intelligence field, are applied to advance an area in forensic biomechanics.

\section{Materials and Methods}

\section{General Method}

The scenario considered here is that the biomechanics expert has been asked to opine about whether the defendant failed to meet a generally accepted standard, which may come from a government regulator, voluntary standards organization, or other source. Suppose the standard is stated in terms of acceptable and unacceptable ranges of some quantity that is expressed as a real number. The standard may be that the quantity is above some threshold, and sometimes it must be below a threshold. The proposed method for developing a Bayesian network to assist in developing the opinion has six steps:

1. Identify the deterministic model based on principles of engineering mechanics. This step is simply constructing a deterministic mathematical engineering mechanics model of the system using established methods from biomechanics [3]. The model should be one that can be represented with algebraic equations or inequalities.

2. Represent model as a directed acyclic graph. Nodes represent variables. Directed edges encode the algebraic relationships between variables. The result should be a directed acyclic graph. If it cannot be constructed as a directed acyclic graph, the method fails; if it can be, proceed to step three.

3. Identify nodes that can be modeled as random variables. There are three obvious sources of uncertainty suitable for inclusion in the model: (1) variability in anthropometric parameters, (2) variability in human performance, and (3) measurement error of model inputs. People come in many shapes and sizes, and statistical methods are commonly used to model anthropometric variation. How a person moves, which drives the kinematic and kinetic inputs to biomechanical models, can be highly variable due to a variety of reasons including noise in the motor control system. Finally, empirical measurements have error and statistical methods are well established for representing the error using probability distributions. Distributions must be selected and parameters specified.

4. Extend the directed acyclic graph to a full Bayesian network. Identify all leaf nodes in the directed acyclic graph that have an outdegree (number of edges directed out of a node) of one. For all of the nodes identified in this step that correspond to variables in step two, apply the corresponding probability distributions. At this point, the Bayesian network is a stochastic implementation of a traditional biomechanical model. Note that, at this point, model inputs are limited to traditional measurements made in biomechanics, and these do not include medical data available in civil litigation case files.

5. Identify outcomes (events) that have occurred in the legal case of interest that are known in hindsight. Civil injury litigation often arises because someone has been injured. Add nodes and edges that model the relationship between variables already in the model and the injury event. 
6. Add node for the probability that a generally accepted standard was exceeded. This is the node that will be used to address the "more likely than not" interpretation of "reasonable scientific certainty" put forward in Burke v. Town of Walpole. For the node added in step five, add a node representing a Boolean variable. Add an edge from the existing node to the new node that does not transform the variable at all; it merely makes the variable available to the new node. Add a node probability table to the new node, such that the Boolean variable takes on a value of true when the variable associated with the incident edge is greater than-or less than, depending on the context-the generally accepted standard for this variable (the direction should be selected so that the variable takes on a value of true if the standard is not met).

\section{Examples}

The inspiration for this project was the realization that a previously published hybrid Bayesian network model of spinal injury during lifting [4] could easily be extended to produce a probability of whether the spinal compression force exceeded a generally accepted threshold. The extended model produced a numerical result that could be directly used to determine if the "more likely than not" criteria was met. Therefore, the first example will be how the model described in Hughes [4] was extended for civil litigation. While this specific example suggests that hybrid Bayesian network modeling may be useful in this context, there remains an open question: "Is the use of Bayesian network modeling idiosyncratic to spinal modeling or can it be generalized for other applications in biomechanics?" To address this, another common area of occupational biomechanics in civil injury litigation was chosen to investigate: a slip resulting in a fall that injures someone. Therefore, a second example of a slip-induced fall injury was selected for modeling and analysis using a hybrid Bayesian network.

\subsection{Spinal Injury During Lifting}

Attorneys seek biomechanics experts to opine about the forces acting on the internal biological tissues associated with the injury involved in litigation. The request can be to opine on whether the forces exceed some generally accepted threshold established by a government agency or consensus standards organization. This is relevant to the question of negligence of the employer. The National Institute for Occupational Safety and Health (NIOSH), which is part of the Centers for Disease Control and Prevention in the United States, issued a guideline of $3400 \mathrm{~N}$ of spinal compression force at the L5/S1 spinal level $[5,6]$. NIOSH stated this was the level at which jobs "are hazardous to all but the healthiest of workers." Therefore, the biomechanist would conduct an analysis of the lifting task the plaintiff claimed caused the injury to determine if the spine experienced more than $3400 \mathrm{~N}$ of compression force. NIOSH estimates of compression force used to develop this threshold were computed using a deterministic static biomechanical model developed by Chaffin [7], which has been nicely presented in a common textbook on occupational biomechanics [3]. The model was two dimensional and had rigid body segments joined by hinges. The body segments were hand/forearm (combined), upper arm, torso/head/neck (combined), pelvis, thigh, lower leg, and foot. Postures for all segments, except the pelvis, were input by the user based on measurements made in the lab or field. L5/S1 intervertebral disk orientation, which defined pelvic orientation, was estimated from the torso and knee angle using a regression model [8]. The mechanical analysis was top-down, meaning that it sequentially computed the moments and forces at the elbow, shoulder, L5/S1 disc, hip, knee, and ankle. Erector spinae muscle force was computed using a simplified anatomic representation of the lumbar region extensor musculature. The reaction force at L5/S1 was decomposed into orthogonal components to get shear and compression.

Hughes [4] implemented Chaffin's model [3] as a hybrid Bayesian network so that model inputs could be treated as random variables. Following publication of the hybrid Bayesian network model, it was observed that the model could easily be extended to directly address the "more likely than not" criterion. The remainder of this subsection describes the method by which the model described in 
Hughes [4] was developed and extended to address the civil litigation "more likely than not" standard of proof. It begins with the first five steps of the methodology proposed in Section 2:

1. Identify the deterministic model based on principles of engineering mechanics. The lifting model described by Chaffin was selected for implementation (it is described above and presented in more detail in $[3,7])$, but the effect of intra-abdominal pressure was not included because its effectiveness depends on breath control [9].

2. Represent model as a directed acyclic graph. Nodes (written in italics) were made for input variables (mass in hands and body angles), joint reaction forces and moments, included knee angle, L5/S1 intervertebral disc angle, and erector spinae force. Directed edges were added to indicate relationships between forces and moments at ends of body segments, static equilibrium at the L5/S1 intervertebral disc, the regression equation relating included knee angle and torso angle to $L 5 / S 1$ disc angle, and the trigonometry required to decompose the L5/S1 reaction force into L5/S1 shear force and L5/S1 compression force components. The disc injury portion of the model was completed by adding directed edges from the L5/S1 compression force and disc compression strength to disc injury nodes.

3. Identify nodes that can be modeled as random variables. Variables associated with input nodes (mass in hands and joint angles) were considered to be appropriately modeled as random variables because of measurement error. Normal probability distributions were selected to model these quantities as well as disc compression strength.

4. Extend the directed acyclic graph to a full Bayesian network. The resulting directed acyclic graph was entered into AgenaRisk software (Agena Ltd., Cambridge, UK). The deterministic mathematical relationships associated with directed edges were also entered to complete the hybrid Bayesian network.

5. Identify outcomes (events) that have occurred in the legal case of interest that are known in hindsight. While workplace factors (weight lifted and body segment angles) can be known prior to injury, the status of the disc injury node was something known in hindsight. By the time the case file gets to the biomechanics expert, the injury had occurred and been documented in the case file based on medical examination and possibly operative notes from the spinal surgery.

The model described in Hughes [4] was developed using these five steps. The model is contained in the upper box (dotted) in Figure 1. The final step, which is the sixth in the process proposed in Section 2, is contained in the lower box of Figure 1:

6. Add node for the probability that a generally accepted standard was exceeded. One node, L5/S1 compression force $>3400 \mathrm{~N}$, representing a Boolean variable was added. It took on a value of true when the L5/S1 compression force exceeded $3400 \mathrm{~N}$. 


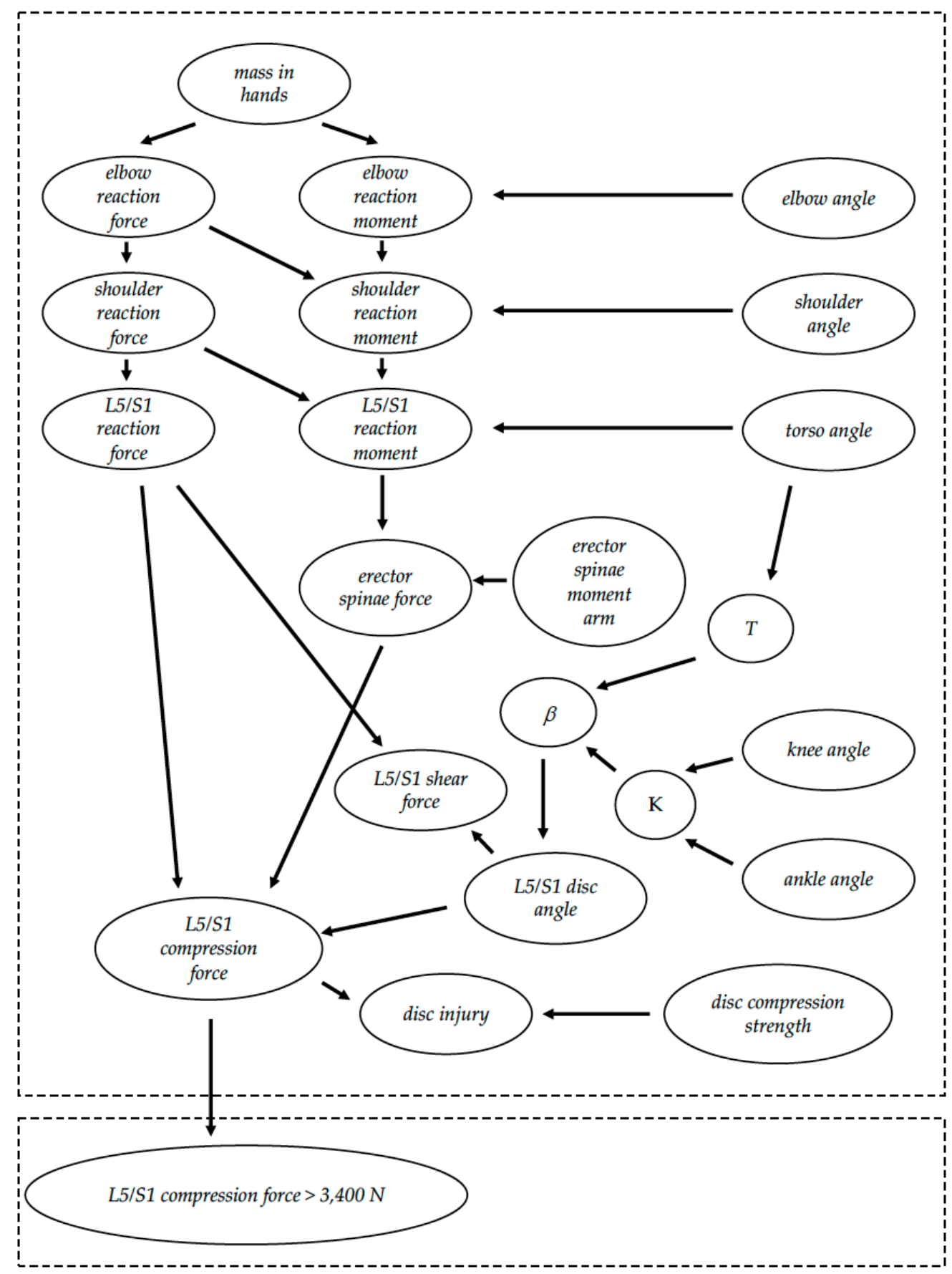

Figure 1. A hybrid Bayesian network developed for computing the probability that L5/S1 compression force exceeds $3400 \mathrm{~N}$. The upper box (dotted) contains the model developed and described in Hughes [4]. This model was developed using steps two through five of the proposed method. The bottom box (dotted) contains the extension made to make this model directly address the "more likely than not" standard used in civil litigation (step six of the method). The Boolean random variable L5/S1 compression force $>3400 \mathrm{~N}$ was added to extend the model, and it takes on the value of true when the variable defined by the node L5/S1 compression force > $3400 \mathrm{~N}$ and it is false otherwise.

\subsection{Injury Resulting from a Slip-Induced Fall}

The second hypothetical example, which was selected to investigate whether the modeling approach described in Section 2 could be extended beyond lifting, involved an injury resulting from a slip-induced fall. Assume that a person was injured in a fall that occurred as a result of a slip while 
walking on a flat surface, and these facts are undisputed. The plaintiff argues that someone or some entity responsible for maintaining the walking surface failed to meet a generally accepted standard of providing sufficient coefficient of friction to prevent a slip and fall. The actual coefficient of friction (ACOF) is the tribological quantity that the expert will opine about. The ACOF is the ratio of the shear force acting along the surface required to generate a slip to the normal force acting on the surface. It is measured using a slip tribometer. The other quantity required in the analysis is the required coefficient of friction (RCOF), which is the ratio of the shear force to normal force acting on the walking surface by the shoe during gait. In engineering theory, a slip occurs when the RCOF exceeds the ACOF. The expert is to opine about whether the ACOF failed to meet a generally accepted standard, suggesting whoever was responsible for maintaining the walking surface was negligent in some fashion. In the United States, a common threshold for the ACOF is 0.5 , based on a proposal by the Occupational Health and Safety Administration [10]. That value will be used here. Since it is impossible for the expert to go back in time and measure the ACOF using a slip tribometer under the actual floor conditions present at the time of the injury, analysis is required. There are models that relate the ACOF and the RCOF to the probability of slipping [10-13], but they do not include the case file evidence that a slip occurred. They produce prior probability estimates that do not account for the fact that a slip has occurred. Therefore, the process described in Section 2 was applied to generate a hybrid Bayesian network that could address the question of whether the ACOF exceeded 0.5 given that a slip occurred:

1. Identify the deterministic model based on principles of engineering mechanics. A simple mechanical model of a slip was used, i.e., a slip occurs when the RCOF exceeds the ACOF.

2. Represent model as a directed acyclic graph. Three nodes were created: RCOF, ACOF, and slip. Directed edges were added from ACOF and RCOF to slip.

3. Identify nodes that can be modeled as random variables. The ACOF can be affected by contaminants on the walking surface [14], and uncertainty about the amount and distributions of these contaminants can introduce uncertainly in estimates of the ACOF. Variation between strides (and between people) also create uncertainty in the RCOF [15]. Authors have modeled both the ACOF and the RCOF as random variables using a variety of distributions $[10,13,16,17]$. Therefore, the nodes, $A C O F$ and $R C O F$, can be modeled as random variables. Lognormal distributions were selected and parameters obtained from Gragg and Yang [13].

4. Extend the directed acyclic graph to a full Bayesian network. The hybrid Bayesian network was implemented in AgenaRisk software. It was completed by entering the nodes, directed edges, probability distributions, and slip model. The slip model was implemented by setting the slip Boolean node slip to take on a value of true if and only if the RCOF was greater than the ACOF.

5. Identify outcomes (events) that have occurred in the legal case of interest that are known in hindsight. In this hypothetical example, the slip variable would be of direct interest to the expert seeking to opine on the ACOF at the time of the slip.

6. Add node for the probability that a generally accepted standard was exceeded. A Boolean node, the $A C O F<0.05$ was added to complete the hybrid Bayesian network (Figure 2). It took on a value of true if and only if the ACOF $<0.5$.

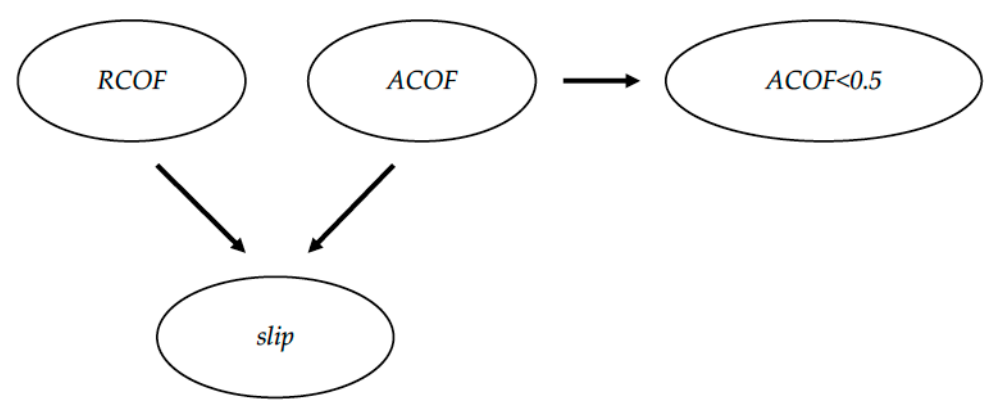

Figure 2. Hybrid Bayesian network developed for a slip event based on the ACOF and the RCOF. 


\section{Results}

\subsection{Lifting Model}

A hypothetical example was analyzed to illustrate the application of the model to developing an opinion based on the NIOSH threshold of $3400 \mathrm{~N}$ for spinal compression force. A stoop lift was selected for analysis. The lifting posture, which was defined as body segment relative to horizontal, was $-68^{\circ}$, $-120^{\circ}, 0^{\circ}, 121^{\circ}$, and $83^{\circ}$ for the elbow, shoulder, torso, knee, and ankle, respectively. The standard deviations, which represent uncertainty in measurement from photographs [18], was $11.8^{\circ}, 7.9^{\circ}, 6.3^{\circ}$, $9.4^{\circ}$, and $9.4^{\circ}$ for the elbow, shoulder, torso, knee, and ankle, respectively. The central element of this simulation that illustrates its usefulness is demonstrated by setting the disc injury Boolean input node to true. Prior to specifying that value, AgenaRisk computed the prior probability of the L5/S1 compression force exceeding $3400 \mathrm{~N}$ (no injury specified condition); setting the value to true produced the posterior probability that incorporated knowledge of disc status. For completeness, disc injury status was also set to false. The mass in hands input mean was varied from 0 to $50 \mathrm{~kg}$ in $5 \mathrm{~kg}$ increments to demonstrate the relationship between hand load and probability of the L5/S1 compression force exceeding $3400 \mathrm{~N}$.

Including injury status in the hybrid Bayesian network analysis strongly affected the probability of L5/S1 spinal compression force exceeding $3400 \mathrm{~N}$ (Figure 3). Although the largest difference in probability predictions was between the disc injury node states of true and false, the most relevant comparison is between the disc injury unspecified and true states because this represented the comparison between what a traditional analysis would produce and an analysis that incorporated information about the injury status of the plaintiff. At a hand load of $25 \mathrm{~kg}$, for example, the probability of exceeding $3400 \mathrm{~N}$ would be 0.40 and 0.61 for the unspecified and true disc injury conditions, respectively. The former value of 0.40 meant that it was less likely than not that the force threshold was exceeded; the probability of 0.61 indicated it was more likely than not. Thus, there was a region of hand loads that lead to two different opinions depending on the disc injury status. However, there were also levels of hand load that produced consistent results for all three disc injury conditions. The probability of exceeding the threshold was less than 0.5 for all disc injury states (true, false, and unspecified) below a hand load of $20 \mathrm{~kg}$; similarly, above $35 \mathrm{~kg}$, both disc injury states produced probability estimates greater than 0.5 for all conditions.

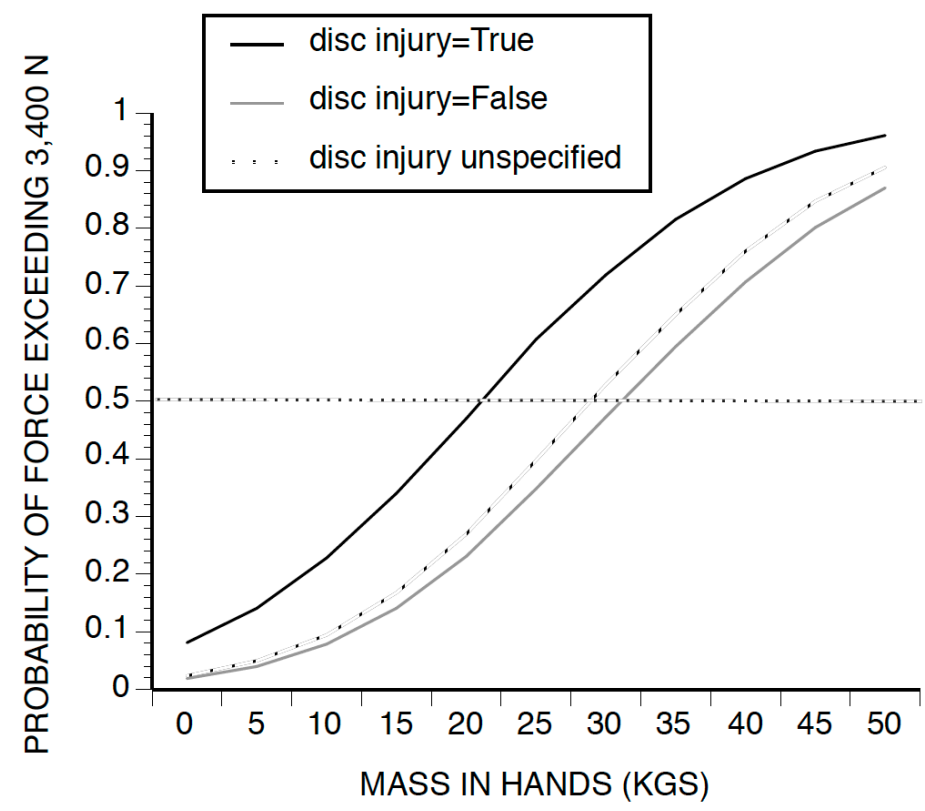

Figure 3. Probability of the L5/S1 compression force exceeding $3400 \mathrm{~N}$ for different evidence (true, false, and unspecified) entered at the disc injury node. 


\subsection{Slip and Fall Model}

Numerical results of the model indicated the powerful effect of including the evidence that the slip event occurred (Figure 4). Similar to other stochastic models of slips [13], the prior probability of a slip occurring given the RCOF and the ACOF distributions was very small $\left(2.7 \times 10^{-7}\right)$. The prior probability of the ACOF being less than 0.5 was 0.01 . After the slip node was set to true, the probability of the ACOF being less than 0.5 increased to 0.68 . The model demonstrated how evidence of a slip occurring could change an expert's opinion about whether the ACOF met the generally accepted threshold. Unlike the lifting example, where a value above the threshold suggested negligence, in this example, it was an ACOF value below 0.5 that suggested negligence. Thus, the expert would be opining on whether the ACOF was less than 0.5 based on the "more likely than not" criterion. The model showed how the opinion would change from a conclusion based on the prior probability ("no") to one based on the posterior probability ("yes").

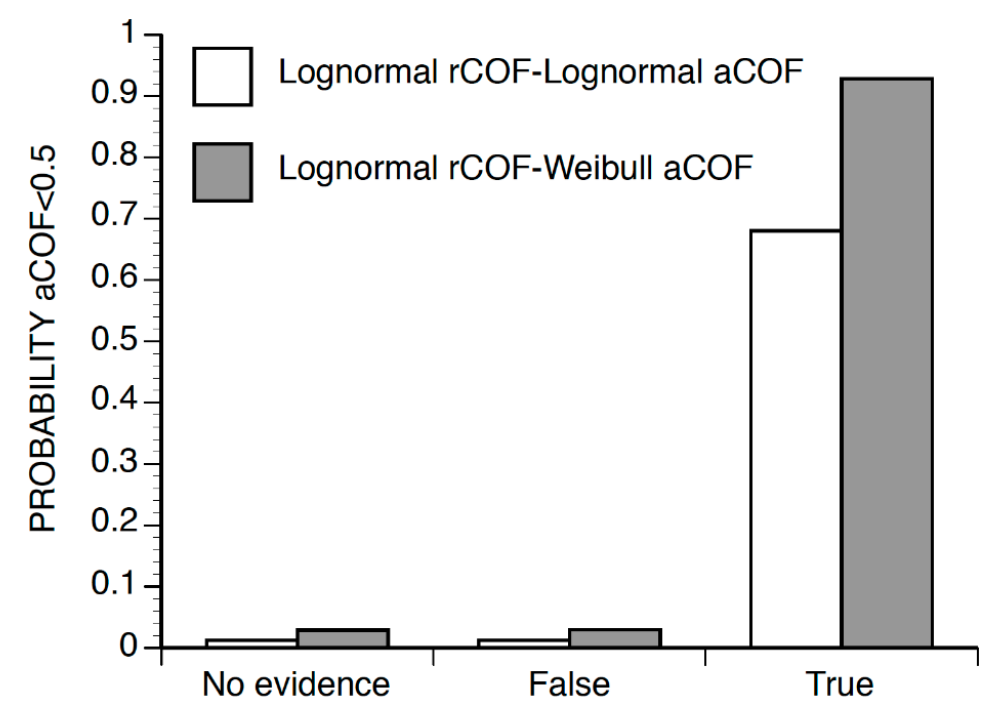

Figure 4. Probability of the ACOF being less than 0.5 when three difference levels of evidence (no evidence, true, and false) were entered at the slip node.

\section{Discussion}

This work describes the experience of developing a hybrid Bayesian network model of lifting [4] and extending it to directly address the "more likely than not" interpretation of "reasonable scientific certainty" in civil litigation proposed in Burke v. Town of Walpole. Furthermore, the method was successfully tested by applying it to another common cause of injury, slip-induced fall injury. Therefore, it appears the proposed method can be useful for aligning deterministic biomechanical models with the needs of an expert witness.

The modeling methodology proposed here can be used in two ways: (1) directly using the two models (slip and fall and spinal injury) in conducting analyses for use in litigation, and (2) applying the methodology to new kinds of injury scenarios. In the first instance, the models would be used similarly to existing methods of biomechanical analyses. Field measurements would be collected, computational analyses would be performed, and a report written. What would be different from existing methods would be an emphasis on quantifying the variability of measurements taken in the field. The variability data is necessary to describe the uncertainty in model parameters, which is a key element of the Bayesian network modeling framework. In an evaluation of lifting, for example, it is important to acknowledge and quantify the variability in estimating body posture from photographs [18]. The second use of the work presented here is applying the methodology to novel biomechanical models. The way to begin applying Bayesian network modeling is to determine the 
source of the uncertainty to be modeled. The uncertainty may be due to measurement error, such as in the postural assessment of photographs made in the field, or from inherent variability in human motor control. Once the source of the variability is known, the analyst can focus on choosing the model variables to treat as random. Finally, it is important to remember that a major strength of this modeling approach is that it can also incorporate information about the existence of an injury. In many personal injury cases, medical details of the injury are not a topic for a biomechanist to opine about, as this has already been addressed by depositions taken under oath by medical professionals. Therefore, the modeler should include a node representing whether the injury occurred or not (Figure 3 illustrated how important this can be for the lifting model).

The novelty of this work can be appreciated by comparing and contrasting it to the literature on artificial intelligence in biomechanics, probabilistic biomechanical models, and Bayesian network modeling in law. In a survey of machine learning papers in human movement biomechanics, Halilaj et al. [19] showed that the number of publications appears to be increasing exponentially. The most commonly used methods were support vector machines, artificial neural networks, generalized linear models, and k-means clustering. Bayesian networks have also been used for supervised machine learning in biomechanics [20-23]. However, the work described here takes a very different approach than machine learning. It uses a tool (a Bayesian network) developed in artificial intelligence in the 1980s by Judea Pearl [24] and others [25-27] to implement stochastic versions of engineering mechanics models found in occupational biomechanics. Rather than relying on feature and outcome data for training in a machine learning framework, it implements a mechanistic stochastically.

Parallel to the evolution of machine learning in biomechanics, stochastic biomechanical modeling advanced from simple Monte Carlo simulations [28-31] to applications of the advanced mean value theorem [32] and Markov chains [33]. However, these modeling approaches do not leverage the power of Bayes Theorem. The Bayesian modeling approach described here allows for incorporating injury status information, which is often a key part of the legal case file being examined by a forensic expert, into the model. Knowing that an injury happened to the plaintiff is a key piece of additional information that is not included in previous stochastic modeling work in biomechanics. Therefore, the work described here extends the literature on stochastic biomechanical modeling.

The proposed modeling approach is also a contribution to the literature on Bayesian network modeling in law because it is one of very few addressing civil litigation. Almost all Bayesian network papers in law have focused on criminal law, with special emphasis on assessing evidence [34-52]. A major methodological difference is that much of the modeling in criminal cases is focused on computing likelihood ratios for competing theories of a legal case [53], while the method proposed here focuses on computing the probability of failing to meet a generally accepted standard.

The primary limitation of this work is that the deterministic models of engineering mechanics analyzed could be represented using algebraic equations and inequalities. While this represents a large class of models used in occupational biomechanics [3], there are biomechanical models that are based on ordinary and partial differential equations. While differential equations can be simulated using discrete time steps and nodes could be created for each state variable at each time step, it may be challenging to compute probabilities using junction tree and dynamic discretization methods. Finite element models require solving large systems of dense linear equations, which are not amenable to hybrid Bayesian network modeling due to the lack of conditional independence between variables. Response surface methods would need to be used to represent finite element model results before implementing as hybrid Bayesian networks. Future work could investigate the application of the method proposed here to these more computationally challenging biomechanical models.

\section{Conclusions}

The modeling work presented here was inspired by the task of biomechanics experts meeting the norms and requirements of the United States legal system, but it generalized beyond the United States. The modeling framework was developed to meet the "more likely than not" criteria because 
the "preponderance of evidence" standard of proof is used in civil cases where biomechanics opinions are often given. The concept of the preponderance of evidence, which is also known as the "balance of probabilities," is also used in England and elsewhere. Therefore, this modeling approach has international applicability.

Funding: This research received no external funding.

Conflicts of Interest: The author declares no conflict of interest. The author is not using these models in any current or pending consulting work/litigation.

\section{References}

1. Babitsky, S.; Mangraviti, J.J; Babitsky, A. The A-Z Guide to Expert Witnessing; SEAK Inc.: Falmouth, UK, 2006.

2. United States Court of Appeals, First Circuit. Burke v. Town of Walpole, 405 F.3d 66 (1st Cir. 2005); United States Court of Appeals, First Circuit: Boston, MA, USA, 2005.

3. Chaffin, D.B.; Andersson, G.B.J.; Martin, B.J. Occupational Biomechanics, 4th ed.; Wiley-Interscience: Hoboken, NJ, USA, 2006.

4. Hughes, R.E. Using a Bayesian network to predict L5/S1 spinal compression force from posture, hand load, anthropometry, and disc injury status. Appl. Bionics Biomech. 2017, 2017, 1-7. [CrossRef]

5. Waters, T.R.; Putz-Anderson, V.; Garg, A.; Fine, L.J. Revised NIOSH equation for the design and evaluation of manual lifting tasks. Ergonomics 1993, 36, 749-776. [CrossRef]

6. National Institute for Occupational Safety and Health. Work Practices Guide for Manual Lifting; Government Printing Office: Washington, DC, USA, 1981.

7. Chaffin, D.B. A computerized biomechanical model-Development of and use in studying gross body actions. J. Biomech. 1969, 2, 429-441. [CrossRef]

8. Anderson, C.K.; Chaffin, D.B.; Herrin, G.D. A study of lumbosacral orientation under varied static loads. Spine 1986, 11, 456-462. [CrossRef] [PubMed]

9. Hagins, M.; Pietrek, M.; Sheikhzadeh, A.; Nordin, M.; Axen, K. The effects of breath control on intra-abdominal pressure during lifting tasks. Spine 2004, 29, 464-469. [CrossRef] [PubMed]

10. Barnett, R.L. "Slip and fall" theory-extreme order statistics. Int. J. Occup. Saf. Ergon. 2002, 8, 135-159. [CrossRef]

11. Hanson, J.P.; Redfern, M.S.; Mazumdar, M. Predicting slips and falls considering required and available friction. Ergonomics 1999, 42, 1619-1633. [CrossRef]

12. Chang, W.-R. A statistical model to estimate the probability of slip and fall incidents. Saf. Sci. 2004, 42, 779-789. [CrossRef]

13. Gragg, J.; Yang, J. Predicting the probability of slip in gait: Methodology and distribution study. Comput. Methods Biomech. Biomed. Eng. 2016, 19, 93-100. [CrossRef]

14. Redfern, M.S.; Bidanda, B. Slip resistance of the shoe-floor interface under biomechanically-relevant conditions. Ergonomics 1994, 37, 511-524. [CrossRef]

15. Redfern, M.S.; Cham, R.; Gielo-Perczak, K.; Gronqvist, R.; Hirvonen, M.; Lanshammar, H.; Marpet, M.; Pai, C.Y.; Powers, C. Biomechanics of slips. Ergonomics 2001, 44, 1138-1166. [CrossRef] [PubMed]

16. Chang, W.R.; Matz, S.; Chang, C.C. The stochastic distribution of available coefficient of friction for human locomotion of five different floor surfaces. Appl. Ergon. 2014, 45, 811-815. [CrossRef] [PubMed]

17. Gragg, J.; Klose, E.; Yang, J. Modelling the stochastic nature of the available coefficient of friction at footwear-floor interfaces. Ergonomics 2017, 60, 977-984. [CrossRef]

18. Liu, Y.; Zhang, X.; Chaffin, D. Preception and visualization of human posture information for computer-aided ergonomic analysis. Ergonomics 1997, 40, 818-833. [CrossRef]

19. Halilaj, E.; Rajagopal, A.; Fiterau, M.; Hicks, J.L.; Hastie, T.J.; Delp, S.L. Machine learning in human movement biomechanics: Best practices, common pitfalls, and new opportunities. J. Biomech. 2018, 81, 1-11. [CrossRef] [PubMed]

20. Van Gestel, L.; De Laet, T.; Di Lello, E.; Bruyninckx, H.; Molenaers, G.; Van Campenhout, A.; Aertbelien, E.; Schwartz, M.; Wambacq, H.; De Cock, P.; et al. Probabilistic gait classification in children with cerebral palsy: A Bayesian approach. Res. Dev. Disabil. 2011, 32, 2542-2552. [CrossRef] [PubMed] 
21. Lo, B.; Pansiot, J.; Yang, G.-Z. Bayesian analysis of sub-plantar ground reaction force with BSN. in Sixth International Workshop on Wearable and Implantable Body Sensor Networks. In Proceedings of the Sixth International Workshop on Wearable and Implantable Body Sensor Networks, Berkeley, CA, USA, 3-5 June 2009.

22. Ma, H.T.; Griffith, J.F.; Yang, Z.; Kwok, A.W.; Leung, P.C.; Lee, R.Y. Kinematics of the lumbar spine in elderly subjects with decreased bone mineral density. Med. Biol. Eng. Comput. 2009, 47, 783-789. [CrossRef]

23. Takenaka, S.; Aono, H. Prediction of Postoperative Clinical Recovery of Drop Foot Attributable to Lumbar Degenerative Diseases, via a Bayesian Network. Clin. Orthop. Relat. Res. 2017, 475, 872-880. [CrossRef]

24. Pearl, J. Probabilistic Reasoning in Intelligent Systems: Networks of Plausible Inference; Morgan Kaufmann: San Francisco, CA, USA, 1988.

25. Cowell, R.G.; Dawid, A.P.; Lauritzen, S.L.; Spiegelhalter, D.J. Probabilistic Networks and Expert Systems; Springer: New York, NY, USA, 1999.

26. Dawid, A.P. Applications of a general propagation algorithm for probabilistic expert systems. Stat. Comput. 1992, 2, 25-36. [CrossRef]

27. Spiegelhalter, D.J.; Dawid, A.P.; Lauritzen, S.L.; Cowell, R.G. Bayesian analysis in expert systems. Stat. Sci. 1993, 8, 219-283. [CrossRef]

28. Gatti, C.J.; Hallstrom, B.R.; Hughes, R.E. Surgeon variability in total knee arthroplasty component alignment: A Monte Carlo analysis. Comput. Methods Biomech. Biomed. Eng. 2014, 17, 1738-1750. [CrossRef] [PubMed]

29. Hughes, R.E.; An, K.N. Monte Carlo simulation of a planar shoulder model. Med. Biol. Eng. Comput. 1997, 35, 544-548. [CrossRef] [PubMed]

30. Mirka, G.A.; Marras, W.S. A stochastic model of trunk muscle coactivation during trunk bending. Spine 1993, 18, 1396-1409. [CrossRef] [PubMed]

31. Lin, C.F.; Gross, M.; Ji, C.; Padua, D.; Weinhold, P.; Garrett, W.E.; Yu, B. A stochastic biomechanical model for risk and risk factors of non-contact anterior cruciate ligament injuries. J. Biomech. 2009, 42, 418-423. [CrossRef]

32. Easley, S.K.; Pal, S.; Tomaszewski, P.R.; Petrella, A.J.; Rullkoetter, P.J.; Laz, P.J. Finite element-based probabilistic analysis tool for orthopaedic applications. Comput. Methods Programs Biomed. 2007, 85, 32-40. [CrossRef]

33. Donnell, D.M.S.; Seidelman, J.L.; Mendias, C.L.; Miller, B.S.; Carpenter, J.E.; Hughes, R.E. A stochastic structural reliability model explains rotator cuff repair retears. Int. Biomech. 2014, 1, 29-35. [CrossRef]

34. Keppens, J.; Schafer, B. Knowledge based crime scenario modelling. Expert Syst. Appl. 2006, 30, $203-222$. [CrossRef]

35. Juchli, P.; Biedermann, A.; Taroni, F. Graphical probabilistic analysis of the combination of items of evidence. Law Probab. Risk 2011, 11, 51-84. [CrossRef]

36. Garbolino, P.; Taroni, F. Evaluation of scientific evidence using Bayesian networks. Forensic Sci. Int. 2002, 125, 149-155. [CrossRef]

37. Gittelson, S.; Biedermann, A.; Bozza, S.; Taroni, F. Bayesian networks and the value of the evidence for the forensic two-trace transfer problem. J. Forensic Sci. 2012, 57, 1199-1216. [CrossRef]

38. Gittelson, S.; Biedermann, A.; Bozza, S.; Taroni, F. Modeling the forensic two-trace problem with Bayesian networks. Artif. Intell. Law 2013, 21, 221-252. [CrossRef]

39. Vlek, C.; Prakken, H.; Renooij, S.; Verheij, B. Building Bayesian networks for legal evidence with narratives: A case study evaluation. Artif. Intell. Law 2014, 22, 375-421. [CrossRef]

40. Vlek, C.; Prakken, H.; Renooij, S.; Verheij, B. A method for explaining Bayesian networks for legal evidence with scenarios. Artif. Intell. Law 2016, 24, 285-324. [CrossRef]

41. Taroni, F.; Biedermann, A.; Garbolino, P.; Aitken, C.G.G. A general approach to Bayesian networks for the interpretation of evidence. Forensic Sci. Int. 2004, 139, 5-16. [CrossRef] [PubMed]

42. Taroni, F.; Biedermann, A. Inadequacies of posterior probabilities for the assessment of scientific evidence. Law Probab. Risk 2005, 4, 89-114. [CrossRef]

43. Smit, N.M.; Lagnado, D.A.; Morgan, R.M.; Fenton, N.E. Using Bayesian networks to guide the assessment of new evidence in an appeal case. Crime Sci. 2016, 5, 9. [CrossRef] [PubMed]

44. Riesen, M.; Serpen, G. Validation of a bayesian belief network representation for posterior probability calculations on national crime victimization survey. Artif. Intell. Law 2008, 16, 245-276. [CrossRef] 
45. Fenton, N.; Neil, M.; Hsu, A. Calculating and understanding the value of any type of match evidence when there are potential testing errors. Artif. Intell. Law 2013, 22, 1-28. [CrossRef]

46. Fenton, N.; Neil, M.; Berger, D. Bayes and the Law. Annu. Rev. Stat. Appl. 2016, 3, 51-77. [CrossRef]

47. Fenton, N.; Neil, M. Bayes and the law. In Risk Assessment and Decision Analysis with Bayesian Networks; Fenton, N., Neil, M., Eds.; CRC Press: Boca Raton, FL, USA, 2013; pp. 407-439.

48. Constantinou, A.C.; Yet, B.; Fenton, N.; Neil, M.; Marsh, W. Value of information analysis for interventional and counterfactual Bayesian networks in forensic medical sciences. Artif. Intell. Med. 2016, 66, 41-52. [CrossRef]

49. Aitken, C.G.G.; Taroni, F. Statistics and the Evaluation of Evidence for Forensic Scientists; John Wiley and Sons: Hoboken, NJ, USA, 2004.

50. Aitken, C.G.G.; Gammerman, A.; Zhang, G.; Connolly, T.; Bailey, D.; Gordon, R.; Oldfield, R. Bayesian Belief Networks with an Application in Specific Case Analysis; Gammerman, A., Ed.; John Wiley and Sons: Hoboken, NJ, USA, 1996.

51. Aitken, C.G.G.; Connolly, T.; Gammerman, A.; Zhang, G.; Bailey, D.; Gordon, R.; Oldfield, R. Statistical modelling in specific case analysis. Sci. Justice 1996, 36, 245-255. [CrossRef]

52. Aitken, C.G.G.; Gammerman, A.J. Probabilistic reasoning in evidential assessment. J. Forensic Sci. Soc. 1989, 29, 303-316. [CrossRef]

53. Buckleton, J.S.; Triggs, C.M.; Champod, C. An extended likelihood ratio framework for interpreting evidence. Sci. Justice 2006, 46, 69-78. [CrossRef]

(C) 2020 by the author. Licensee MDPI, Basel, Switzerland. This article is an open access article distributed under the terms and conditions of the Creative Commons Attribution (CC BY) license (http://creativecommons.org/licenses/by/4.0/). 